\title{
Correlating Structure and Function of Metal Nanoparticles for Catalysis
}

\author{
Liang Zhang ${ }^{\mathrm{a}, \mathrm{c}}$, Rachael M. Anderson ${ }^{\mathrm{a}, \mathrm{b}}$, Richard M. Crooks ${ }^{\mathrm{a}, \mathrm{b}}$, Graeme \\ Henkelman ${ }^{\mathrm{a}, \mathrm{c}, \mathrm{b}}$ \\ ${ }^{a}$ Department of Chemistry, The University of Texas at Austin, Austin, TX 78712-0165, United States \\ ${ }^{b}$ Texas Materials Institute, The University of Texas at Austin, Austin, TX 78712-0165, United States \\ ${ }^{c}$ Institute for Computational Engineering and Sciences, The University of Texas at Austin, Austin, TX \\ 78712-0165, United States
}

\begin{abstract}
This paper summarizes several studies correlating the structure and function of nanoparticle catalysts. Three types of alloy nanoparticles are considered, random alloy, core@ shell and alloy-core@shell structures. In the first two cases, the focus is to build theoretical models to understand previous experimental results. In the latter case, calculations play a greater role in leading the development of nanoparticle catalysts. We demonstrate that iteration between theory and experiment can facilitate an understanding of nanoparticle catalysts and reduce the time and effort involved in the design of new catalysts.
\end{abstract}

Keywords: nanoparticle, structure, function, alloy, catalysts, core-shell

\section{Introduction}

The science and technology of catalysis is particularly important at this time due to the energy and environmental challenges facing society. Research in the 1990s, showing surprising activity of Au nanoparticles, has largely motivated a search for new catalytic materials on the nanoscale with properties that are different from their bulk counterparts. [1] Another significant factor in the development of new catalysts has been the growth of computing power and improvements in theoretical methods to help understand experiments at the atomic scale and to provide guidelines for catalyst design. Experiments, demonstrating the high activity of nanoparticle catalysts, have inspired the development of theoretical methods for calculating reaction mechanisms and screening for new catalysts. Iterating between theory and experiment is a promising strategy for understanding nanoparticle catalysis and reducing the cost of the development cycle for new catalysts. This paper reviews some of our recent theoretical studies of multi-metallic nanoparticles catalysis, and shows how, with a close coupling to experiment, we are able to refine our models and test our predictions.

Dendrimer-encapsulated nanoparticles (DENs) provide an excellent model system which can be synthesized and characterized at the atomic scale for direct comparison

Email address: henkelman@utexas.edu (Graeme Henkelman) 
(a) $\mathrm{G}_{n}-\mathrm{OH}\left(\mathrm{M}_{1}^{2+}, \mathrm{M}_{2}^{2+}\right)$

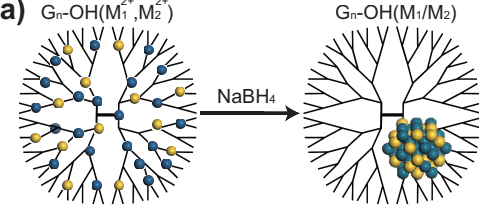

(b)

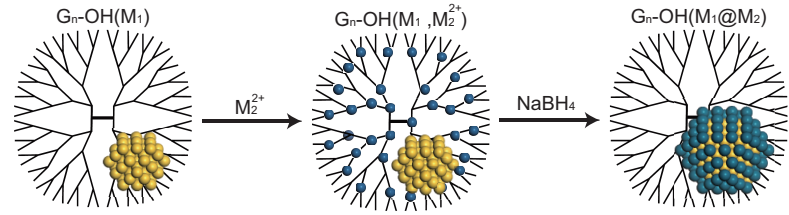

(c)

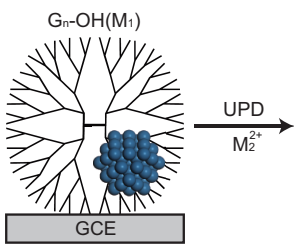

$\mathrm{G}_{\mathrm{n}} \mathrm{OH}\left(\mathrm{M}_{1} @ \mathrm{M}_{2}\right)$

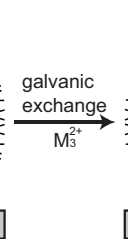

$\mathrm{G}_{\mathrm{n}}-\mathrm{OH}\left(\mathrm{M}_{1} @ \mathrm{M}_{3}\right)$

(d)
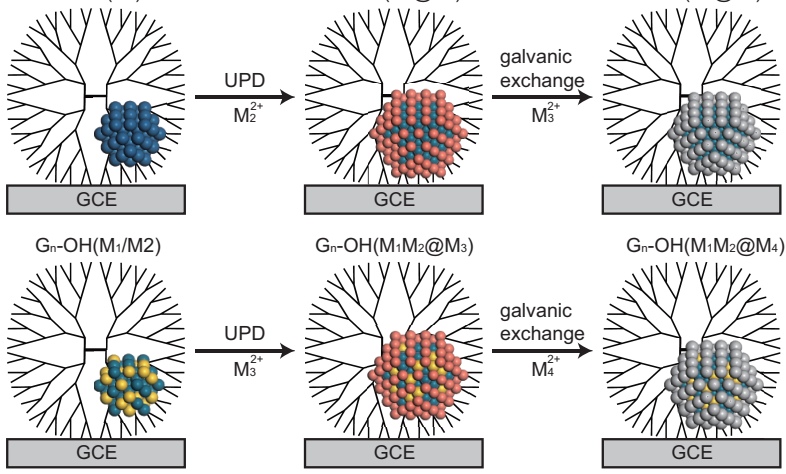

Gn-OH(M $\left.\mathrm{M}_{1} \mathrm{M}_{2} @ \mathrm{M}_{4}\right)$

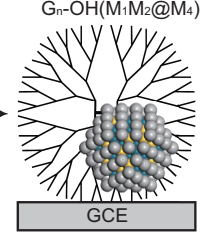

Figure 1: Routes to synthesize different metallic DENs, including: (a) random alloy, (b) core@ shell via sequential reduction, (c) core@ shell and (d) alloy-core@shell via underpotential deposition and subsequent galvanic exchange.

with theory. DENs are synthesized by sequestering metal ions within the interior of, for example, poly(amidoamine) (PAMAM) dendrimers, followed by chemical reduction of the metal-ion/dendrimer complex with a reducing agent such as borohydride. [2, 3, 4, 5] Two features of DENs make them a good model system for correlating theory and experiment. First, their size, composition, and structure can be precisely controlled. $[6,7]$ Second, the dendrimers stabilize the encapsulated nanoparticles and provide a handle for linking them to an electrode surface, but they do not interfere significantly with reactions on the particle surface. [8]

Figure 1 illustrates the synthetic routes to form random alloy $[9,7,10,11,12]$, core-shell [13, 14, 15, 16], and alloy-core@shell DENs [17]. Random alloy DENs are prepared by a co-complexation method, where two types of metal cations are reduced simultaneously to form an alloy particle. Core@ shell nanoparticles are produced by a sequential reduction or underpotential deposition (UPD) of a shell metal onto the core. Galvanic exchange, which is also known as redox displacement, is an elegant technique which can then be used to replace reactive elements in the DENs with more noble ones, [18] increasing the variety of shells that are available for the DENs synthesis.

Alloy nanoparticles have a broad range of applications for many catalytic processes. In this paper we focus on the oxygen reduction reaction (ORR). The ORR is the cathode 


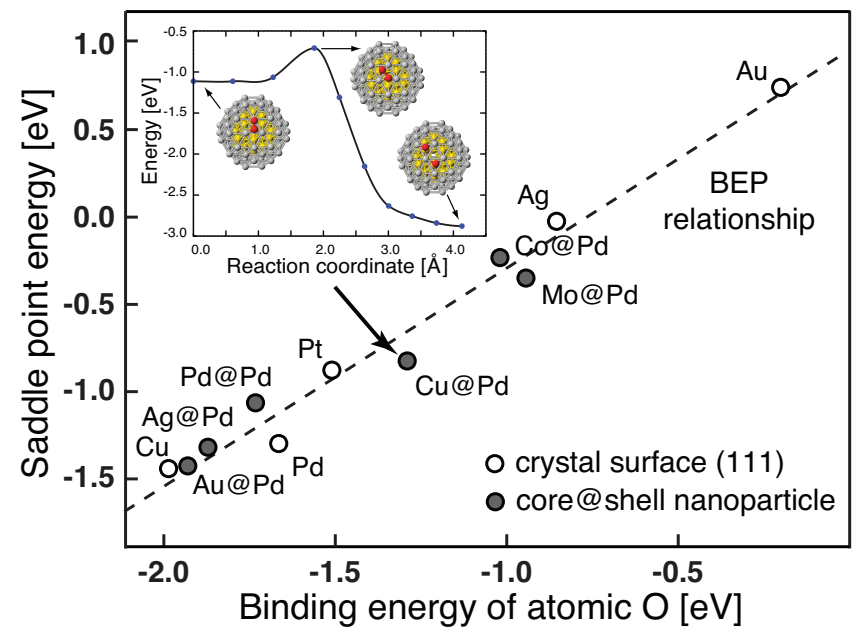

Figure 2: The saddle point energy for oxygen dissociation on Pd-shelled particles and single-crystal surfaces plotted as a function of $\mathrm{O}$ binding energy. The linear trend is a BEP relationship. Particles with barriers and binding energies near $\operatorname{Pt}(111)$ are promising catalysts for the ORR. Reproduced with permission from Ref. [19].

reaction of proton-exchange membrane fuel cells. It involves at least two elementary processes, $\mathrm{O}_{2}$ dissociation and the subsequent removal of the dissociated species by further reduction to $\mathrm{H}_{2} \mathrm{O}$. ORR activity can be measured experimentally using electrochemical techniques, including cyclic voltammetry $(\mathrm{CV})$ and rotating disk voltammetry (RDV). Theoretically, the ORR activity of a surface is understood to correlate with the $\mathrm{O}$ binding energy. Pioneering work by Nørskov and co-workers have established a volcano-shaped correlation between the O binding energy and ORR activity. [20, 21] On the strong-binding side of the volcano, oxygen species over-bind to the catalyst surface and limit the kinetics of product formation. On the weak-binding side of the volcano the reaction is limited by oxygen dissociation and adsorption. Pt offers the optimal tradeoff of the pure metals and the peak of the volcano corresponds to an oxygen binding energy which is slightly weaker than on a Pt(111) surface. The Underlying reason that oxygen binding is a good reactivity descriptor is that there is a BrønstedEvans-Polanyi (BEP) correlation between the binding and transition state energies, so that a single descriptor can describe both limits. In Fig. 2, Tang et. al. show the BEP relationship between the $\mathrm{O}_{2}$ dissociation barrier and $\mathrm{O}$ binding energy for a 79 atom Pd-shelled nanoparticle (NP79) and single-crystal (111) transition metal surfaces. [19] Thus a similar trade off between the dissociation barrier and weak product binding is expected for ORR on (111) facets of small size nanoparticles.

In the following, we consider several nanoparticle alloys and seek to find structures with oxygen binding energies, and hence ORR activities, that approach or exceed that of Pt. 


\section{Random Alloy Nanoparticles}

The random alloy structure is one of the most conventional forms of bimetallics, where two elements are randomly or nearly randomly dispersed in the material. Random alloy DENs can be synthesized by the aforementioned co-reduction method shown in Fig. 1(a). A number of random alloys DENs, including $\mathrm{Pd} / \mathrm{Au}, \mathrm{Pd} / \mathrm{Cu}, \mathrm{Pd} / \mathrm{Pt}$ and $\mathrm{Au} / \mathrm{Ag}$, in the size range of 1-2 nm have been successfully synthesized. [11, 10, 7, 12, 9] The catalytic properties of a random alloy nanoparticle can be tuned by adjusting the ratio of the component elements. Studies on large particles (which behave similar to bulk) have revealed that adding small amounts of metals which bind oxygen strongly (e.g. $\mathrm{Co}, \mathrm{Ni}$ and $\mathrm{Cu}$ ) can lower the oxygen binding to more noble metals (Pt or Pd) and improve their ORR activity. [22, 23, 24, 25]

\subsection{Geometric Effects in Pd/Pt random alloy NP79}

Figure 3(a) shows the experimentally measured ORR activity of Pd/Pt DENs as a function of composition. [7] An enhancement of ORR activity was observed by the addition of small amounts of Pd to a Pt DEN. The average oxygen binding energy was calculated using DFT for Pd/Pt random alloys in a slab and NP79 geometry as a function of $\mathrm{Pd} / \mathrm{Pt}$ composition. [26] A nearly linear binding energy trend is found for $\mathrm{Pd} / \mathrm{Pt}$ slabs with increasing Pt ratio. However when the nanoparticle size is reduced to 79 atoms, the linear trend develops curvature and has a maximum activity at Pd:Pt of 1:1. Moreover, this nonlinear trend disappears when the NP79 structure is frozen in its structure before oxygen binding, indicating the important role of geometry relaxation in determining the catalytic activity of small alloy nanoparticles (see Fig. 3(b)) To better understand this geometric relaxation effect, the total binding energy $E_{\text {tot }}$ was decomposed into two parts, (i) the oxygen affinity $E_{\mathrm{a}}$ calculated as the oxygen binding energy to the frozen particle, and (ii) the subsequent energy of the geometric relaxation $E_{\mathrm{d}}$ of the particle due to the presence of bound oxygen. This energy decomposition, shown in Fig. 3(c,d), shows that $E_{\mathrm{a}}$ is insensitive to geometry whereas $E_{\mathrm{d}}$ is strongly size dependent. The value of $E_{\mathrm{d}}$ becomes comparable to $E_{\mathrm{a}}$ for the 79-atom nanoparticle, for which structural relaxation is much easier than in a slab geometry. The curvature of $E_{\mathrm{d}}$ is a consequence of Pt-Pt bonding, which varies quadratically with the fraction of $\mathrm{Pt}$ atoms in the particle, [26] is key to understanding why $\mathrm{Pt} / \mathrm{Pd}$ alloys are more active than either pure Pt or Pd nanoparticles.

The structural deformation of Pt nanoparticles induced by atomic oxygen binding stabilizes oxygen species bound to the surface and causes Pt NP79 to over-bind oxygen and reduce the ORR activity. We describe this properties of Pt (and also Au) as being soft with respect to oxygen binding. Our calculations show that introducing a harder element ( $\mathrm{Ag}, \mathrm{Cu}$ or Pd) disrupts the Pt-Pt bonding so that the particle resists deformation upon oxygen adsorption which in turn reduces the binding energy and increases ORR activity.

\subsection{Electronic Effects in $P d / C$ C random alloy $N P 79$}

While geometric relaxation is important to understand the ORR activity trend of $\mathrm{Pd} / \mathrm{Pt}$ random alloy nanoparticles, electronic effects are dominant in random alloy 

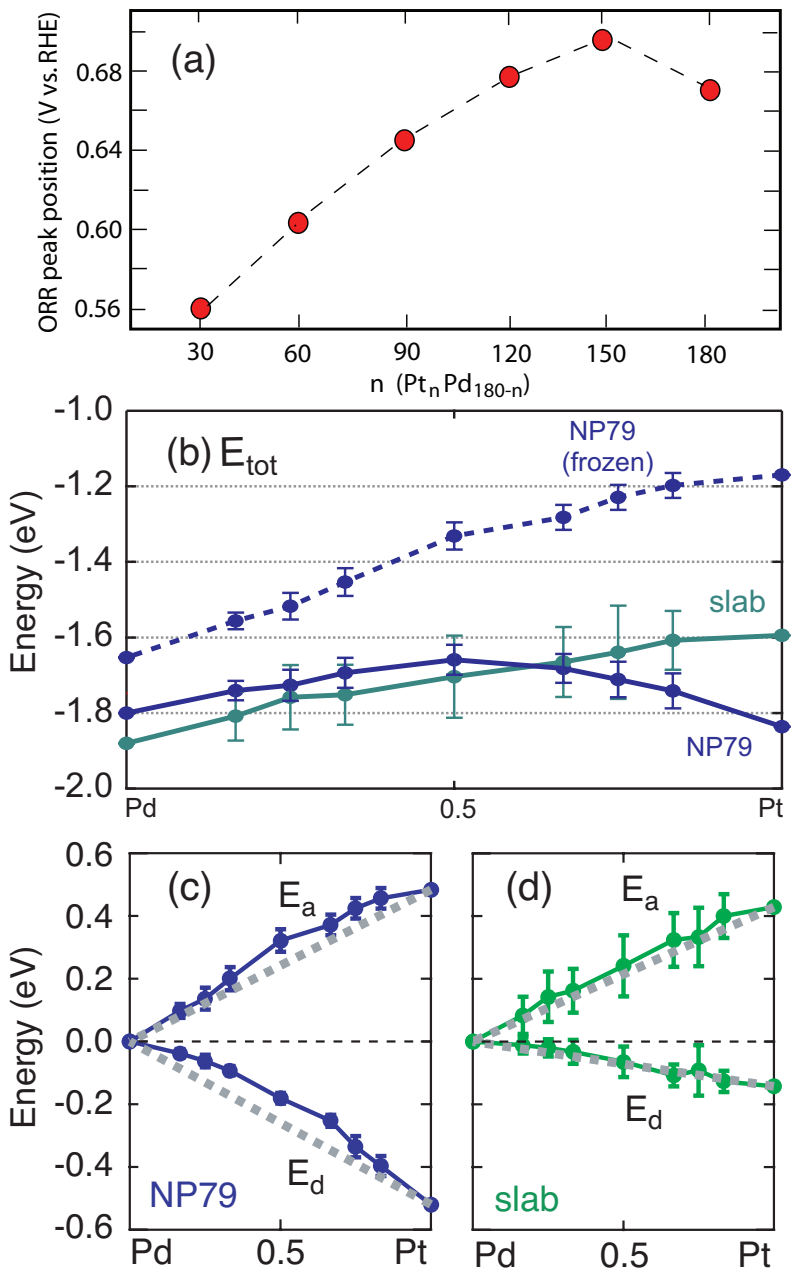

Figure 3: (a) Experimental ORR peak current position for various $\mathrm{Pt}_{n} \mathrm{Pd}_{180-n}$ compositions (reproduced from Ye and Crooks [7]). (b) The average oxygen binding energy as a function of $\mathrm{Pd} / \mathrm{Pt}$ alloy composition, with error bars indicating the standard deviation over random alloy structures. An activity maximum is seen at an intermediate composition for the NP79 structure. This maximum is due to a geometric relaxation of the surface atoms because it is not present in the slab geometries or when the NP79 structure is held frozen upon oxygen binding. The total oxygen binding energy and the energy decomposition of the $\mathrm{Pd} / \mathrm{Pt}$ random alloy in the forms of (c) NP79 and (d) slab at various compositions. For ease of comparison, all of the curves were shifted to zero at the left. The grey dashed lines represent the linear interpolations from the pure metal data. Reprinted (adapted) with permission from Ref. [26]. Copyright (2011) American Chemical Society.

nanoparticles formed by two hard elements, such as Pd and $\mathrm{Cu}$. Geometric and electronic effects were studied to determine their contributions for tuning the oxygen binding. The geometric effect is independent of the $\mathrm{Cu}$ ratio, and therefore only the electronic effect is responsible for the oxygen binding trend. The oxygen binding energy trend of $\mathrm{Pd} / \mathrm{Cu}$ random alloy NP79 was studied for a range of compositions $(\mathrm{Cu} \%=0$, 


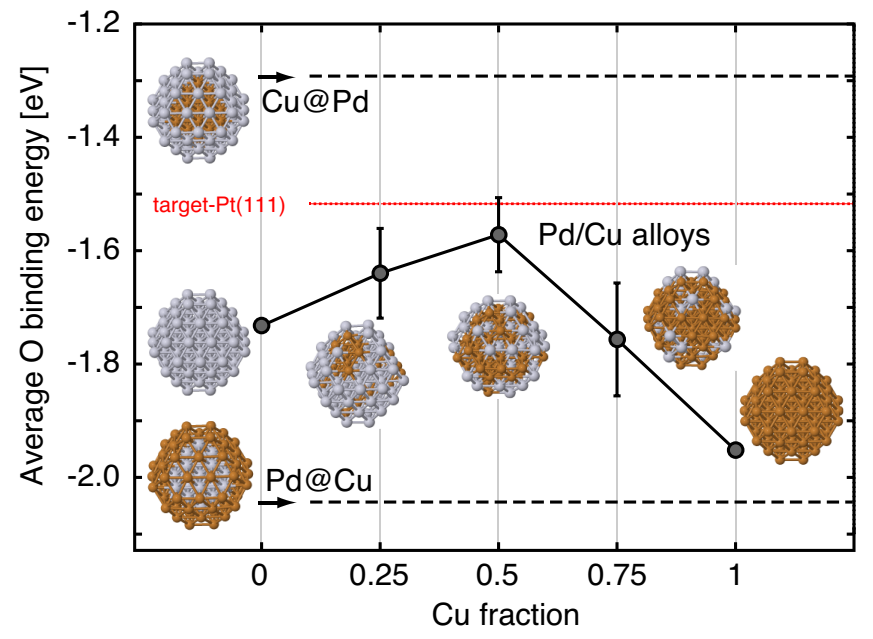

Figure 4: Average binding energy of oxygen on alloy $\mathrm{Pd} / \mathrm{Cu}$ nanoparticles, with error bars indicating the standard deviation of 80 binding sites with different random alloy structures. Using this binding energy as a reactivity descriptor for the ORR indicates a peak in activity for random alloy particles at 1:1 compositions of $\mathrm{Cu}$ (dark color) and Pd (light color). Reprinted with permission from Ref. [27]. Copyright (2011) American Chemical Society.

0.25, 0.5, 0.75 and 1), as shown in Fig. 4. [27] Although Cu NP79 itself binds oxygen more strongly than Pd NP79, the addition of $\mathrm{Cu}$ to Pd initially weakens the average oxygen binding until it reaches the extremum at $\mathrm{Pd}: \mathrm{Cu}$ ratio of $1: 1$. While all the $\mathrm{Pd} / \mathrm{Cu}$ random NP79 alloys bind oxygen more strongely than $\mathrm{Pt}(111)$ (dashed line in Fig. 4), the highest ORR activity should be achieved at the weakest oxygen binding composition, that is a $\mathrm{Pd}: \mathrm{Cu}$ ratio near 1:1. This optimal ratio from our calculation matches well with previous experiments, where $\mathrm{Cu}$ has been found to promote the ORR activity of $\mathrm{Pd}$ at a ratio of $50 \%$. [28, 29]

When $\mathrm{Cu}$ is alloyed into $\mathrm{Pd}$, charge shifts from $\mathrm{Cu}$ to $\mathrm{Pd}$ since $\mathrm{Cu}$ has a higher Fermi level. This charge redistribution lowers the $\mathrm{Pd} d$-band and raises the $\mathrm{Cu} d$ band. Thus, the $\mathrm{Cu}$ atoms neighboring $\mathrm{Pd}$ decrease the $\mathrm{Pd}-\mathrm{O}$ bond strength, while $\mathrm{Pd}$ atoms neighboring $\mathrm{Cu}$ increase $\mathrm{Cu}-\mathrm{O}$ binding. These effects are not symmetric, however, as shown in Fig. 5, where the oxygen binding was decomposed into Pd-O and $\mathrm{Cu}-\mathrm{O}$ interactions as a function of the $\mathrm{Cu}$ ratio according to the $d$-band model. [30] The slope of the $\mathrm{Pd}-\mathrm{O}$ interaction, $m_{\mathrm{Pd}-\mathrm{O}}$, is larger in magnitude than the $\mathrm{Cu}-\mathrm{O}$ slope, $m_{\mathrm{Cu}-\mathrm{O}}$. In other words, the alloying of $\mathrm{Pd}$ and $\mathrm{Cu}$ weakens the $\mathrm{Pd}-\mathrm{O}$ interaction more than it strengthens the $\mathrm{Cu}-\mathrm{O}$ interaction. The average binding to an alloy particle can be written as a linear combination of $\mathrm{Pd}-\mathrm{O}$ and $\mathrm{Cu}-\mathrm{O}$ interactions, weighted by the fraction of each metal in the particle. The $\mathrm{Pd}-\mathrm{O}$ and $\mathrm{Cu}-\mathrm{O}$ interactions can be estimated 


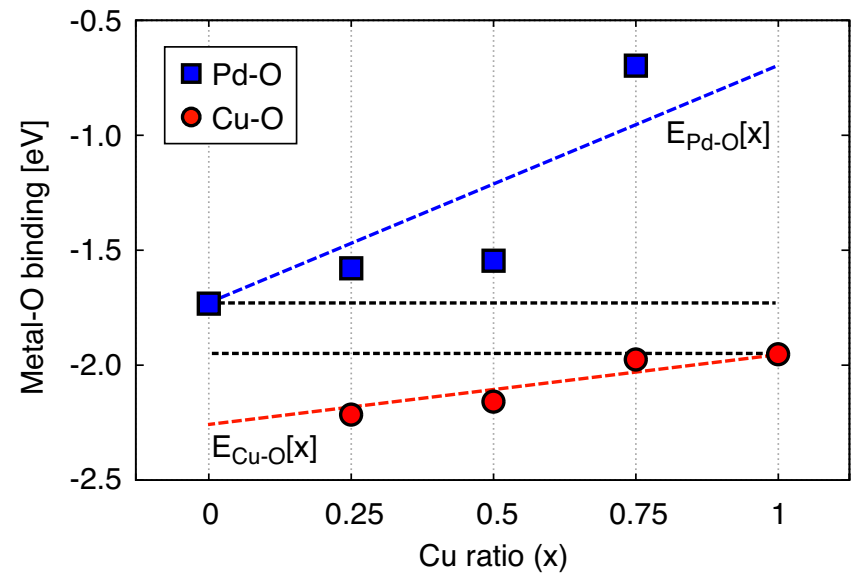

Figure 5: Pd-O binding (blue squares) and the $\mathrm{Cu}-\mathrm{O}$ binding (red circles) for alloy particles with different ratios of $\mathrm{Cu}$. The $\mathrm{Cu}-\mathrm{O}$ binding changes by a small amount, whereas the Pd-O binding is largely reduced by the addition of $\mathrm{Cu}$. Reprinted with permission from Ref. [27]. Copyright (2011), American Chemical Society.

Table 1: Oxygen Binding Energy (eV) of Core-shell NPs for Pd/Au, Pd/Cu and Pd/Ir systems

\begin{tabular}{ccccccc}
\hline \hline$E b_{\mathrm{O}}(\mathrm{eV})$ & $\mathrm{Pd} @ \mathrm{Pd}$ & $\mathrm{X} @ \mathrm{Pd}$ & $\mathrm{X} @ \mathrm{X}$ & $\mathrm{Pd} @ \mathrm{X}$ & $\begin{array}{c}\mathrm{X} @ \mathrm{Pd}- \\
\mathrm{Pd} @ \mathrm{Pd}\end{array}$ & $\begin{array}{c}\mathrm{Pd} @ \mathrm{X}- \\
\mathrm{X} @ \mathrm{X}\end{array}$ \\
\hline $\mathrm{Pd} / \mathrm{Au}$ & -1.73 & -2.03 & -0.60 & 0.05 & -0.30 & 0.65 \\
$\mathrm{Pd} / \mathrm{Cu}$ & -1.73 & -1.31 & -1.95 & -2.04 & 0.42 & -0.09 \\
$\mathrm{Pd} / \mathrm{Ir}$ & -1.73 & -1.56 & -2.01 & -2.33 & 0.17 & -0.32 \\
\hline \hline
\end{tabular}

as a linear function of composition using the slopes $m_{\mathrm{M}-\mathrm{O}}$,

$$
\begin{aligned}
E_{b}[x] & =(1-x) E_{\mathrm{Pd}-\mathrm{O}}[x]+x E_{\mathrm{Cu}-\mathrm{O}}[x] \\
& =(1-x)\left(E_{\mathrm{Pd}-\mathrm{O}}^{0}+x m_{\mathrm{Pd}-\mathrm{O}}\right) \\
& +x\left(E_{\mathrm{Cu}-\mathrm{O}}^{0}+(1-x) m_{\mathrm{Cu}-\mathrm{O}}\right) \\
& =(1-x) E_{\mathrm{Pd}-\mathrm{O}}^{0}+x E_{\mathrm{Cu}-\mathrm{O}}^{0} \\
& +\left(x-x^{2}\right)\left(m_{\mathrm{Pd}-\mathrm{O}}+m_{\mathrm{Cu}-\mathrm{O}}\right),
\end{aligned}
$$

where $x$ is the composition of $\mathrm{Cu}$ and $E_{\mathrm{M}-\mathrm{O}}^{0}$ is the binding to a pure particle of metal $\mathrm{M}$. In the final expression, the first two terms are linear interpolations between the binding at the pure metal particles, and the last term is a quadratic function that describes the relative change in binding due the metals' influence on each other. The difference in magnitude of $m_{\mathrm{Pd}-\mathrm{O}}$ and $m_{\mathrm{Cu}-\mathrm{O}}$ gives rises to the nonlinear binding trend with a curvature towards weak binding at intermediate compositions.

We expect the above non-linear binding trend to be a general property of adsorbate binding to random alloys, providing a prescription for tuning catalytic activity through 


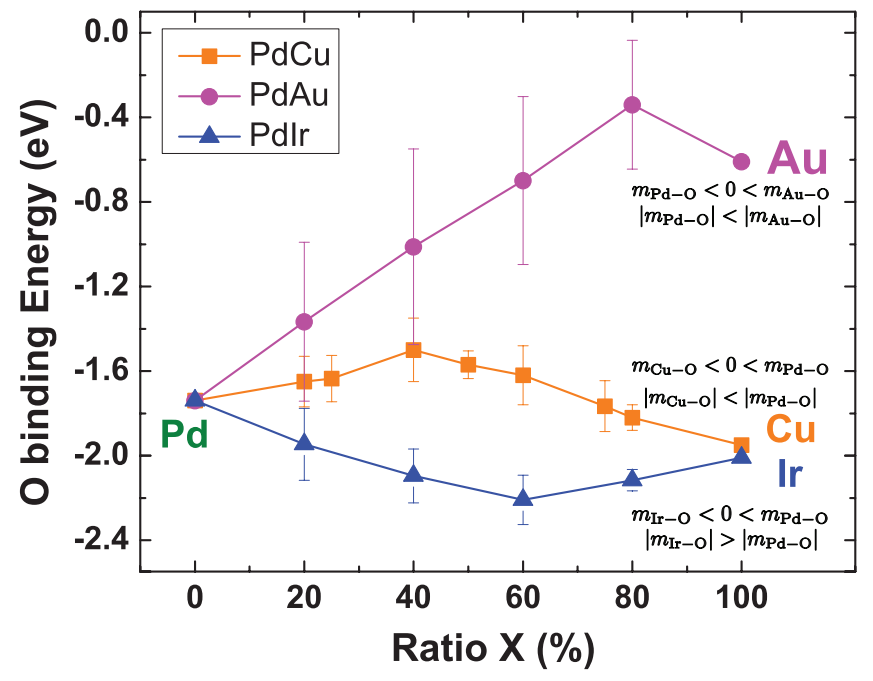

Figure 6: The average $\mathrm{O}$ binding energy trend of $\mathrm{Pd} / \mathrm{X}(\mathrm{X}=\mathrm{Au}, \mathrm{Cu}, \mathrm{Ir})$ random alloy with different ratio of $\mathrm{X}$ in the particles.

alloying. The curvature is determined by the sign and relative magnitude of $m_{\mathrm{M}-\mathrm{O}}$, which can be estimated from the oxygen binding energy on core@ shell nanoparticles. As shown in Fig. 6, $\mathrm{Pd} / \mathrm{X}(\mathrm{X}=\mathrm{Au}, \mathrm{Cu}, \mathrm{Ir})$ random alloy NPs all exhibit non-linear oxygen binding trends. The oxygen binding trend for $\mathrm{Pd} / \mathrm{Ir}$ alloys has the opposite curvature of $\mathrm{Pd} / \mathrm{Cu}$ and $\mathrm{Pd} / \mathrm{Au}$. This can be understood by considering, for example, the Pd/Au alloy. Au has a lower Fermi level than Pd so charge transfers from $\mathrm{Pd}$ to $\mathrm{Au}$ when they are alloyed. Table 1 shows that replacing the core of Pd@Pd with Au enhances the O binding while Pd@Au binds O more weakly than Au@Au. Thus, $m_{\mathrm{Pd}-\mathrm{O}}$ is negative and $m_{\mathrm{Au}-\mathrm{O}}$ is positive. Furthermore, $\left|E b_{\mathrm{Au} @ \mathrm{Pd}}-E b_{\mathrm{Pd} @ \mathrm{Pd}}\right|<$ $\left|E b_{\mathrm{Pd} @ \mathrm{Au}}-E b_{\mathrm{Au} @ \mathrm{Au}}\right|$ so that the magnitude of $m_{\mathrm{Au}-\mathrm{O}}$ is larger than $m_{\mathrm{Pd}-\mathrm{O}}$. Therefore, the oxygen binding trend of $\mathrm{Pd} / \mathrm{Au}$ has a negative curvature since $-\left(m_{\mathrm{Pd}-\mathrm{O}}+m_{\mathrm{Au}-\mathrm{O}}\right)<0$ (see Fig. 6). A similar argument can also be applied to the $\mathrm{Pd} / \mathrm{Cu}$ and $\mathrm{Pd} / \mathrm{Ir}$ systems. In the $\mathrm{Pd} / \mathrm{Cu}$ system, $m_{\mathrm{Pd}-\mathrm{O}}>0, m_{\mathrm{Cu}-\mathrm{O}}<0$ and $\left|m_{\mathrm{Cu}-\mathrm{O}}\right|<\left|m_{\mathrm{Pd}-\mathrm{O}}\right|$, the oxygen binding trend shows a negative curvature. While, in $\mathrm{Pd} / \mathrm{Ir}$ random alloy nanoparticles, $m_{\mathrm{Pd}-\mathrm{O}}>0, m_{\mathrm{Ir}-\mathrm{O}}<0$ and $\left|m_{\mathrm{Ir}-\mathrm{O}}\right|>\left|m_{\mathrm{Pd}-\mathrm{O}}\right|$ giving rise to a positive curvature.

\section{Core-shell Nanoparticles}

Core@ shell nano-structures are important because they exhibit tunable properties arising from the influence of a core metal on the shell. [19, 31, 32, 33, 34] This phenomenon has been applied to electrocatalytic $[32,33,35]$ and spectroscopic applications [34], Early examples demonstrating the importance of Pt-shell nanoparticles as active electrocatalysts for the ORR were reported by Adzic and coworkers. [32, 33] The relationship between bimetallic nanoparticle structure and catalytic activity has been correlated to DFT calculations by a number of groups. [36, 37, 35, 38] 


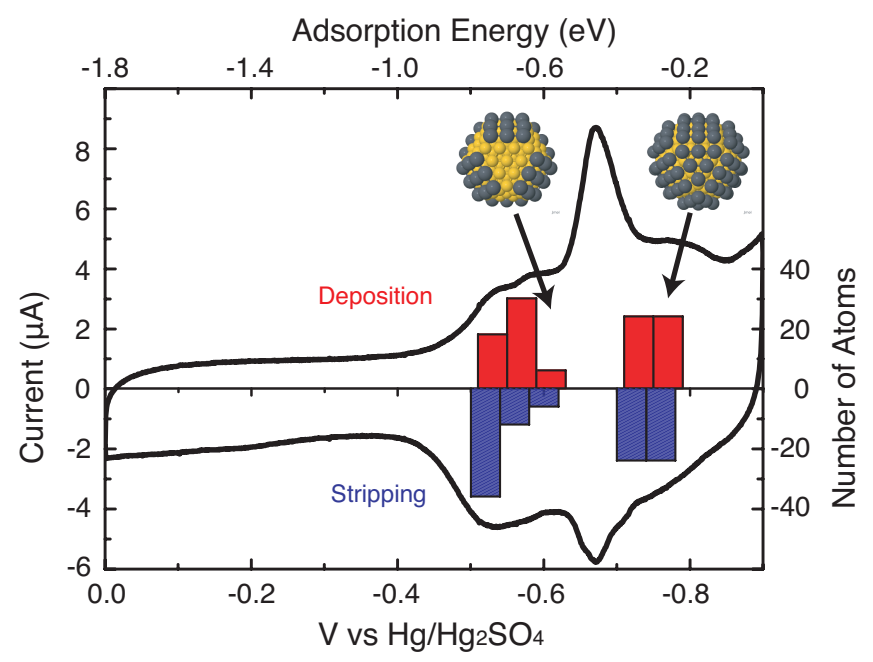

Figure 7: Cyclic voltammetry showing the Pb UPD process at a $\mathrm{Au}_{147}$ DEN-modified glassy carbon electrode. The DFT-calculated potentials for Pb deposition (red bars) and stripping (blue bars) are also shown. Reproduced from Ref. [15] by permission of The Royal Society of Chemistry.

Preparation of core-shell DENs is typically achieved by sequential synthesis, as illustrated in Fig. 1(b,c). In the first step, the core is prepared by homogeneous reduction of a dendrimer/metal ion monometallic precursor. After that, shell atoms are formed on the core cluster by either chemical reduction or UPD. Chemical reduction results in less control of the shell thickness but is able to cover low-coordinated sites (corner/edge) that are usually considered exposed in UPD. UPD provides a systematic scheme to generate a well-defined monolayer shell. [39, 40, 41] In order to have UPD of metal $M_{1}$ onto $M_{2}, M_{1}$ should have stronger interaction with $M_{2}$ than with itself. Thus under a certain applied voltage, deposition of $\mathrm{M}_{1}$ occurs exclusively on $\mathrm{M}_{2}$. Since different crystallographic planes of DENs give rise to UPD waves at different electrochemical potentials, UPD complemented with extended X-ray absorption fine structure (EXAFS) spectroscopy and DFT simulation can be used to tune the shell structure of DENs. Below, we show examples of correlating experiment and DFT in understanding the structures and catalytic function of core@shell nanoparticles.

\section{1. $\mathrm{Pb} U P D$ on $A u_{147}$}

The $\mathrm{Au}_{147}$ DENs were modeled as cuboctahedral particles having (100) and (111) facets. [15] DFT calculations indicate that Pb UPD occurs on the (100) facet before the (111) facet. The average adsorption energy of $\mathrm{Pb}$ on (100) was found to be $0.1 \mathrm{eV}$ per $\mathrm{Pb}$ atom stronger than on the (111) facet, showing that $\mathrm{Pb}$ adlayers on $\mathrm{Au}_{147}(100)$ are more stable than those on $\mathrm{Au}(111)$. Additionally, an atom-by-atom deposition of $\mathrm{Pb}$ onto $\mathrm{Au}_{147}$ was modeled with DFT. $E_{a d}(n)$, the energy required to successively add the $n^{\text {th }} \mathrm{Pb}$ atom to the surface of $\mathrm{Au}_{147}$, was referenced to the binding energy of $\mathrm{Pb}$ on a bulk $\mathrm{Pb}$ surface. A theoretical UPD potential for each deposition event was then 


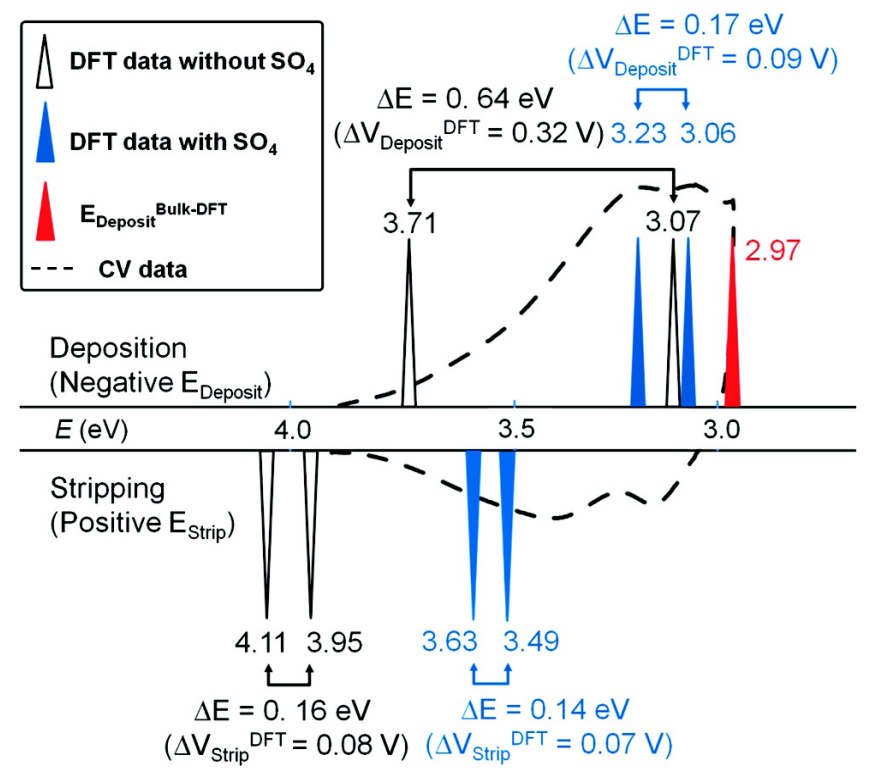

Figure 8: DFT calculated Cu deposition and stripping energies for the various models with the experimentally obtained Cu UPD CV overlaid for comparison (black dashed line). Reprinted (adapted) with permission from Ref. [42]. Copyright (2012) American Chemical Society.

calculated as,

$$
V_{\mathrm{Pb}}^{\mathrm{DFT}}=V_{\mathrm{Pb}-\mathrm{bulk}}^{\mathrm{Exp}}-\frac{1}{2} E_{a d}(n) .
$$

Here $V_{\mathrm{Pb}-\text { bulk }}^{\mathrm{Exp}}$ is the experimentally measured $\mathrm{Pb}$ bulk deposition potential $(-0.90 \mathrm{~V}$ vs $\mathrm{Hg} / \mathrm{Hg}_{2} \mathrm{SO}_{4}$ ), and the factor of $1 / 2$ accounts for the two-electron $\mathrm{Pb}$ deposition and stripping process. Figure 7 provides an overlay of a Pb UPD voltammogram and the energy for deposition and stripping of Pb calculated by DFT. Good agreement is observed between the $\mathrm{CV}$ and the calculated histogram of $\mathrm{Pb}$ adsorption energies. The potentials of the two most prominent $\mathrm{Pb}$ stripping peaks, measured using the $\mathrm{Au}_{147^{-}}$ modified electrode, are at -0.69 and $-0.54 \mathrm{~V}$, where DFT simulation shows stripping events on (111) at $-0.75 \mathrm{~V}$ and (100) at $-0.54 \mathrm{~V}$. All of these observations are consistent with our contention that $\mathrm{Au}_{147} \mathrm{DENs}$ have a cuboctahedral structure, where the (100) and (111) facets are present while (110) facets are absent. The assignment of the UPD peaks provides the appropriate voltages for preparation of core@shell particle with only certain facets covered. By holding the voltage at -0.85 and $-0.63 \mathrm{~V}, \mathrm{Au} @ \mathrm{~Pb}$ with complete shell (both (100) and (111) covered) and partial shell (only (100) covered) can be synthesized, as illustrated by the structures shown in Fig. 7.

\section{2. $C u U P D$ on $P t_{147}$}

In a related study, we aimed to cover specific facets of Pt DENs using Cu UPD. $[13,42]$ The same cuboctahedral structure was used to model the $\mathrm{Pt}_{147}$ DENs. Similarly to $\mathrm{Pb}$ on $\mathrm{Au}, \mathrm{Cu}$ atoms are preferentially deposited on $\mathrm{Pt}(100)$ facets first and then on 

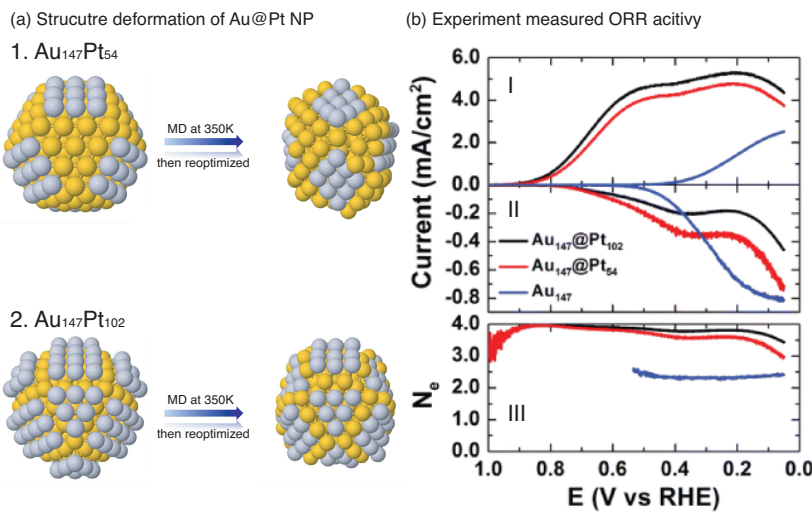

(c) O Binding Sites and Binding Energy (BE) of Au@Pt NP
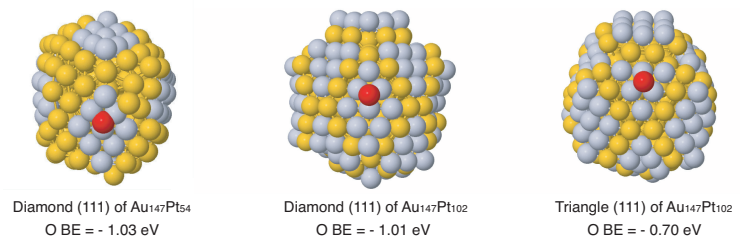

Figure 9: (a) DFT-calculated structures for $\mathrm{Au}_{147} @ \mathrm{Pt}_{54}$ and $\mathrm{Au}_{147} @ \mathrm{Pt}_{102}$ DENs. (bI) ORR polarization curves for the indicated DEN-modified glassy carbon electrodes. (bII) Ring currents arising from the oxidation of peroxide generated at the disk electrode during the ORR. (bIII) The apparent number of electrons calculated from the disk and ring currents. The electrolyte solution was $\mathrm{O}_{2}$-saturated $0.10 \mathrm{M} \mathrm{HClO}_{4}$, the scan rate was $20 \mathrm{mVs}^{-1}$, and the rotation rate was 1600 RPM. (c) Oxygen binding sites and energies for $\mathrm{Au}_{147} @ \mathrm{Pt}_{54}$ and $\mathrm{Au}_{147} @ \mathrm{Pt}_{102}$ DENs. Reproduced from Ref. [15] with permission of The Royal Society of Chemistry

the $\mathrm{Pt}(111)$ facets. The $\mathrm{Cu}$ stripping process was exactly the opposite of the deposition, with $\mathrm{Cu}$ from the Pt(111) facet desorbing first. A similar DFT calculation of the UPD potential was performed for $\mathrm{Cu}$ on $\mathrm{Pt}$, yet the computed binding energies of $\mathrm{Cu}$ to the Pt nanoparticles (in vacuum) did not match those observed in the experiments. However, by considering the competitive binding of the $\mathrm{SO}_{4}$ counter ions (present in the electrolyte) for the Pt@Cu DENs, the theoretical results lined up much better with experiment.

Figure 8 shows the calculated potentials for $\mathrm{Cu}$ UPD and stripping with and without $\mathrm{SO}_{4}$ adsorbed to the Pt DEN surface. The calculated results are overlaid onto an experimental voltammogram. In the presence of $\mathrm{SO}_{4}$ ligands, $\mathrm{Cu}$ atoms exhibit a weakened interaction with $\mathrm{Pt}(100)$ as compared to bare $\mathrm{Pt}_{147}$. The UPD shifts for $\mathrm{Cu}$ stripping are calculated to be 0.33 and $0.25 \mathrm{~V}$ for the $\mathrm{Pt}(100)$ and $\mathrm{Pt}(111)$ facets, respectively. These potentials are much closer to the corresponding experimentally observed UPD shifts of 0.29 and $0.15 \mathrm{~V}$, illustrating the importance of ligand interactions in this system.

\section{3. $A u_{147} @ P t_{54}$ and $A u_{147} @ P t_{102}$}

$\mathrm{Au}_{147} @ \mathrm{Pt}$ (core@shell) DENs were synthesized by transferring the aforementioned $\mathrm{Au}_{147} @ \mathrm{~Pb}_{54}$ and $\mathrm{Au}_{147} @ \mathrm{~Pb}_{102} \mathrm{DEN}$-functionalized electrode into a solution of $\mathrm{Pt}^{2+}$. 
[15] This operation results in galvanic exchange of the Pb UPD shells for Pt, and conversion of the $\mathrm{Au}_{147} @ \mathrm{~Pb}$ DENs to $\mathrm{Au}_{147} @ \mathrm{Pt}$ DENs. The amount of $\mathrm{Pb}$ deposited by UPD determines the amount of Pt on the particle surface. The relaxed structure of $\mathrm{Au}_{147} @ \mathrm{Pt}$ DENs having a complete Pt shell (111 and 100 facets covered) and a partial Pt shell (just the 100 facets covered) were calculated using DFT (Fig. 9(a)). Subsequently, the relaxed structures were used as starting points for DFT molecular dynamics (MD) simulations. These were carried out at $350 \mathrm{~K}$ over $10 \mathrm{ps}$ and showed that surface Pt covering the (100) facet of the Au particle distorted into a (111)-like diamond configuration. The diamond structure is $-0.2 \mathrm{eV} / \mathrm{Pt}$ atom more favorable than the nine atom square $\mathrm{Pt}(100)$ facet.

$\mathrm{Au}_{147} @ \mathrm{Pt}$ DENs having partial and full Pt shells were investigated as electrocatalysts for the ORR. Figure 9(b) shows that $\mathrm{Au}_{147} @$ Pt DENs having partial and full shells had specific activities (at $0.65 \mathrm{~V}$ vs. RHE) of 2.70 and $2.84 \mathrm{~mA} / \mathrm{cm}^{2}$, respectively; a difference of only 5\%. The similarity in activity for the ORR is supported by oxygen binding calculations on the diamond shaped $\mathrm{Pt}(111)$ surfaces, as illustrated in Fig. 9(c). On a $\operatorname{Pt}(111)$ facet from the partially decorated particle, the oxygen binding energy is $-1.03 \mathrm{eV}$ and on a $\mathrm{Pt}(111)$ facet from the fully covered particle, the oxygen binding energy is $-1.01 \mathrm{eV}$. This corroborates the experimental finding that the extent of Pt surface coverage does not significantly change the activity of the particles for the ORR. The compressed diamond Pt facets have promising catalytically active sites for reactions where conventional Pt may be poisoned by intermediates, e.g. CO. For example, Iyyamperumal et. al. reported an enhanced electrocatalytic activity of formic acid oxidation on this $\mathrm{Au}_{147} @ \mathrm{Pt}$ DEN structure where the deformed Pt facets with a compressed Pt-Pt bonds suppress the indirect pathway of formic acid oxidation and largely reduces the $\mathrm{CO}$ poisoning. [43]

\section{Alloy-core@shell Nanoparticles}

As shown in the previous two sections, random-alloy and core@ shell are two structures that have been well-studied to search for bimetallic catalysts. They are often studied because of the opportunity to tune electrocatalytic properties by controlling the structure of the particles. However, there are some shortcomings of these two structures from the viewpoint of particle synthesis and design. Variations in the core@shell structures are discrete in chemical compound space (elements can only be changed by integer atomic numbers) so that the properties of such particles can not be tuned precisely. As shown in Fig. 2, none of the single core@Pd NP79 achieve the same oxygen binding as $\mathrm{Pt}(111)$.

The properties of the random alloy structure, on the other hand, can be finely tuned by varying the composition of the components. However the presence of reactive metals on the surface of the alloy nanoparticle could be unstable under reaction conditions and dissolve into solution. The combined alloy-core@shell structure aims to take advantage of the strengths of the alloy and core@shell particles, and avoid their flaws. Noble metal shells (e.g. Pt, Pd) are stable during synthesis and characterization, and the alloy core offers the opportunity to tune the electronic and geometric properties of the shell by changing its composition. Similar structures have been studied by the Stamenkovic and Adzic groups. [23, 44, 45] In this section, we show how the catalytic 

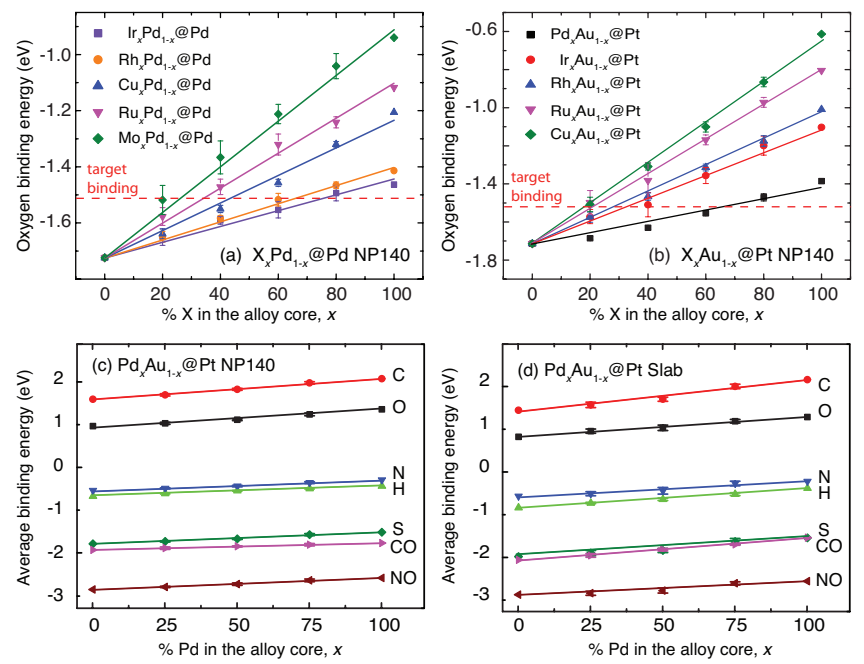

Figure 10: (a) Oxygen binding on $\mathrm{X}_{x} \mathrm{Pd}_{1-x} @ \mathrm{Pd} \mathrm{NP} 140$ (X= Ir, Rh, Cu, Ru and Mo). Reprinted (adapted) with permission from Ref. [46]. Copyright (2012) American Chemical Society. (b) Oxygen binding on $\mathrm{X}_{x} \mathrm{Au}_{1-x} @ \mathrm{Pt} \mathrm{NP140}$ (X= Pd, Ir, Rh, Ru and Cu. Reprinted (adapted) with permission from Ref. [17]. Copyright (2013) American Chemical Society. (c) Average binding trends of seven different adsorbates (C, $\mathrm{O}, \mathrm{N}, \mathrm{H}, \mathrm{S}, \mathrm{CO}$ and NO) on $\mathrm{Pd}_{x} \mathrm{Au}_{1-x} @ \mathrm{Pt} \mathrm{NP} 140$ and (d) $\mathrm{Pd}_{x} \mathrm{Au}_{1-x} @ \mathrm{Pt}$ slab. Linear correlations between the binding of adsorbates to the shell and the alloy core composition of alloy-core@shell NP are found, regardless of the shell metal $(a, b)$, the core metals combination, or the adsorbate molecules and size (c, d).

properties of alloy-core@ shell particles are tuned by the core composition. The predictive power of first principles theory in leading the design cycle for novel materials is also demonstrated here for the ORR.

\subsection{Linear binding correlation of alloy-core@ shell nanoparticles}

The average oxygen binding energy at $\mathrm{Pd} / \mathrm{X}(\mathrm{X}=\mathrm{Ir}, \mathrm{Rh}, \mathrm{Cu}, \mathrm{Ru}$ and $\mathrm{Mo})$ alloy core with Pd shell nanoparticles are studied as a function of the ratio of metal $\mathrm{X}$ in the alloy core, as shown in Fig. 10(a). [46] The red dashed line marks the oxygen binding on $\mathrm{Pt}(111)$, which is chosen as the target value. $\mathrm{X} @ \mathrm{Pd}(\mathrm{X}=\mathrm{Ir}, \mathrm{Rh}, \mathrm{Cu}, \mathrm{Ru}$ and $\mathrm{Mo})$ bind oxygen too strongly as compared to $\mathrm{Pt}(111)$, while $\mathrm{Cu} @ \mathrm{Pd}$ binds oxygen too weakly - they are on the opposite branches of the volcano plot. All of these particles are expected to have lower activity as compared with $\mathrm{Pt}(111)$. Our calculations show that the oxygen binding energy can be weakened linearly by mixing $\mathrm{Cu}$ into these cores. As demonstrated in Fig. 10(b-d), this linear binding correlation is independent of types of core or shell metals, adsorbate molecules, size of particles, thereby providing a general description for tuning principle of alloy-core@ shell nanoparticles. [17, 47]

For alloy-core@shell nanoparticles $\mathrm{X}_{x} \mathrm{Y}_{1-x} @ \mathrm{Z}$, the binding energy can be estimated from a linear combination of two single-core@shell nanoparticles X@Z and Y@Z by,

$$
E b(x)=x E b_{\mathrm{X} @ \mathrm{Z}}+(1-x) E b_{\mathrm{Y} @ \mathrm{Z}} .
$$

This linear tuning mechanism offers a new scheme for catalyst design. Taking the ORR for example, the target oxygen binding energy of $\mathrm{X}_{x} \mathrm{Y}_{1-x} @ \mathrm{Z}$ can be achieved by 
alloying a metal X and Y, where X@Z and Y@Z are on the opposite sides of the target value. The optimal ratio $\mathrm{x}^{*}$ for $\mathrm{X}_{x} \mathrm{Y}_{1-x} @ \mathrm{Z}$ to achieve target binding is given by,

$$
x^{*}=\frac{E b^{*}-E b_{\mathrm{Y} @ \mathrm{Z}}}{E b_{\mathrm{X} @ \mathrm{Z}}-E b_{\mathrm{Y} @ \mathrm{Z}}},
$$

where $E b^{*}$ is the target binding.

\subsection{Pd/Au@Ptfor ORR catalyst}
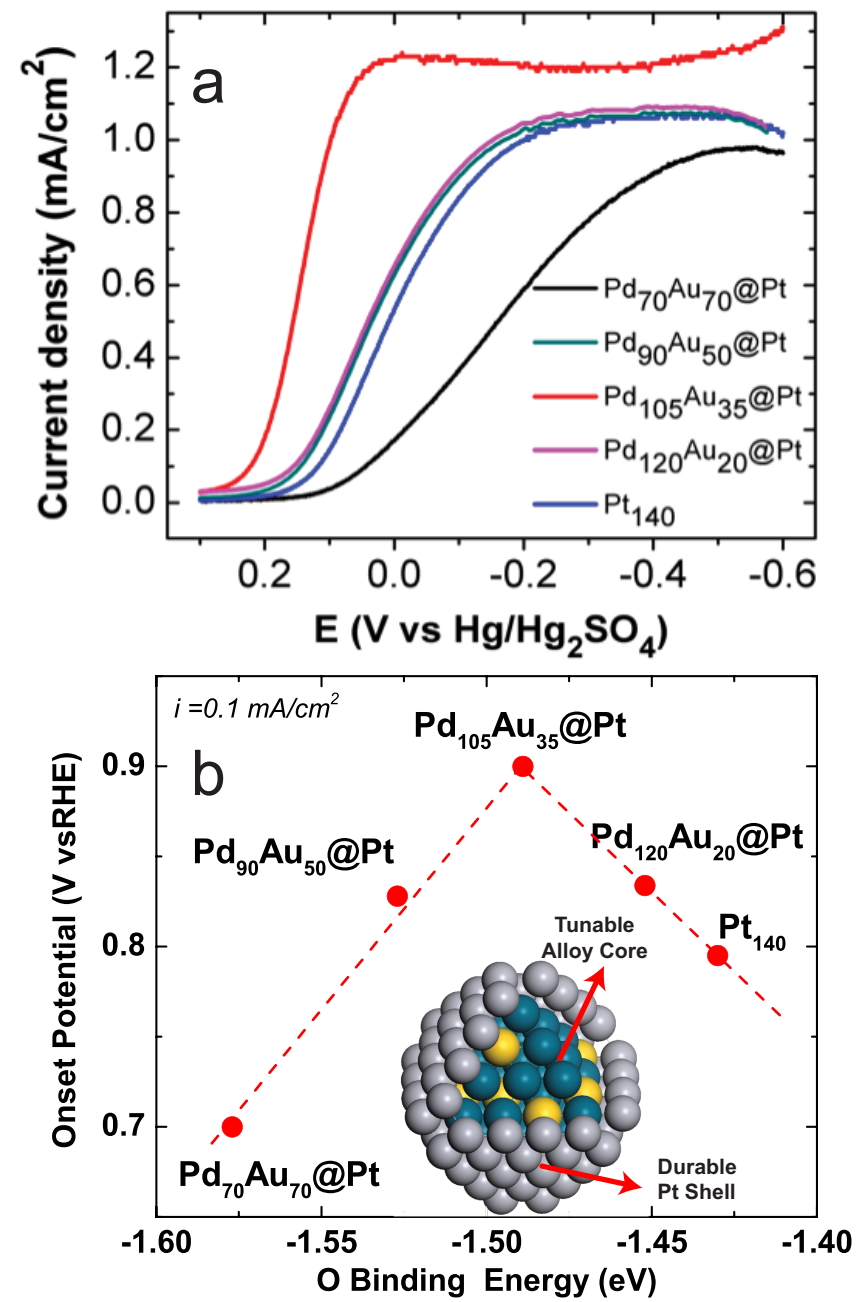

Figure 11: (a) Rotating disk voltammograms for glassy carbon electrodes modified with $\mathrm{Pd}_{n} \mathrm{Au}_{140-n} @ \operatorname{Pt}(\mathrm{n}$ $=70,90,105,120)$ and $\mathrm{Pt}_{1} 40$ DENs. (b) Onset potential for the ORR at $\mathrm{Pd}_{x} \mathrm{Au}_{1-x} @ \mathrm{Pt} @ \mathrm{Pt}$ DENs measured by RDVs and plotted as a function of the corresponding oxygen binding energy calculated by DFT. Reprinted (adapted) with permission from Ref. [17]. Copyright (2013) American Chemical Society. 
Following the above design principle, several alloy-core compositions with a $\mathrm{Pt}$ shell emerge as good ORR catalysts. The optimal compositions can be obtained from Fig. 10(b). One such promising structure is $\mathrm{Pd}_{0.72} \mathrm{Au}_{0.28} @ \mathrm{Pt}$. Based on our theoretical prediction, we synthesized a series of PdAu@Pt DENs with different Pd:Au ratios in the alloy core, as illustrated in Fig. 1(d). The Pd/Au random alloy core was prepared by co-reduction. Then $\mathrm{Cu}$ UPD was conducted on the Pd/Au random alloy DENs modified electrode to form a homogenous $\mathrm{Cu}$ shell. Finally, Pd/Au@Pt DENs were then synthesized by a subsequent galvanic exchange, replacing the $\mathrm{Cu}$ shell with Pt. [17]

The ORR activity of these PdAu@Pt DENs was determined using RDV, by measuring the onset potential where the current density reached $0.1 \mathrm{~mA} / \mathrm{cm}^{2}$. [17] Figure 11(b) plots the RDV measured ORR onset potential against the corresponding oxygen binding energy calculated from DFT, exhibiting a volcano-like activity trend. Notably, data for Pd@Pt DENs is not shown on Fig. 11 because there was core/shell inversion, which was confirmed by EXAFS and DFT.[16] Alloying Au to the Pd-core not only optimized the catalytic activity but also enhanced its stability. The peak activity was achieved with $75 \% \mathrm{Pd}$ in the core, in perfect agreement with our prediction from the linear binding model. As shown in the above section, this linearly tuning mechanism is a general property of alloy-core@ shell nanoparticles. Therefore, similar catalyst design scheme based on alloy-core@shell nanoparticles is expected to be transferable to other important catalytic processes.

\section{Conclusions}

We systematically studied structure-function relationships on alloy DENs having random alloy, core@shell and alloy-core@shell structures. For random alloy nanoparticles, we found that geometric and electronic effects play an important role in the oxygen binding trend of $\mathrm{Pd} / \mathrm{Pt}$ and $\mathrm{Pd} / \mathrm{Cu}$ random alloy NP79, respectively. The oxygen binding trend of $\mathrm{Pd} / \mathrm{Pt}$ consistent with that observed experimentally. In the case of core@shell nanoparticles, theory and experiment were coupled together to understand the structure and their corresponding catalytic performance. Partial shell nanoparticles have a significant portion of their surface made up of bimetallic interfaces. By choosing appropriate pairs of metals, these interfacial sites can be designed to avoid competition between adsorbate binding of reactants, leading to a high activity. [48] Distortion of Pt facets on Au@Pt DENs were found to aid in reducing Pt poisoning. For alloy-core@shell nanoparticles, novel structures were proposed first theoretically and then subsequently tested experimentally. The close correlation between theory and experiment is shown to facilitate the understanding of nanoparticle catalysis and reduce the effort involved in the development cycle of promising new catalysts.

\section{Acknowledgments}

This work was supported by the Chemical Sciences, Geosciences, and Biosciences Division, Office of Basic Energy Sciences, Office of Science, U.S. Department of Energy (Contract DE-FG02-13ER16428). Computing time was provided by the National 
Energy Research Scientific Computing Center and the Texas Advanced Computing Center.

[1] M. Haruta, M. Daté, Advances in the catalysis of au nanoparticles, Appl. Catal. A 222 (2001) 427-437.

[2] D. Yamamoto, S. Watanabe, M. T. Miyahara, Coordination and reduction processes in the synthesis of dendrimer-encapsulated pt nanoparticles, Langmuir 26 (4) (2010) 2339-2345.

[3] R. W. J. Scott, O. M. Wilson, R. M. Crooks, Synthesis, characterization, and applications of dendrimer-encapsulated nanoparticles, J. Phys. Chem. B 109 (2) (2005) 692-704.

[4] H. Lang, R. A. May, B. L. Iversen, B. D. Chandler, Dendrimer-encapsulated nanoparticle precursors to supported platinum catalysts, J. Am. Chem. Soc. 125 (48) (2003) 14832-14836.

[5] M. Bernechea, S. García-Rodríguez, P. Terreros, E. de Jesús, J. L. G. Fierro, S. Rojas, Synthesis of coreshell ptru dendrimer-encapsulated nanoparticles. relevance as electrocatalysts for co oxidation, J. Phys. Chem. C 115 (4) (2011) $1287-$ 1294.

[6] H. Ye, J. A. Crooks, R. M. Crooks, Effect of particle size on the kinetics of the electrocatalytic oxygen reduction reaction catalyzed by pt dendrimerencapsulated nanoparticles, Langmuir 23 (23) (2007) 11901-11906.

[7] H. Ye, R. M. Crooks, Effect of elemental composition of ptpd bimetallic nanoparticles containing an average of 180 atoms on the kinetics of the electrochemical oxygen reduction reaction, J. Am. Chem. Soc. 129 (12) (2007) 3627-3633.

[8] H. Ye, R. M. Crooks, Electrocatalytic o2 reduction at glassy carbon electrodes modified with dendrimer-encapsulated pt nanoparticles, J. Am. Chem. Soc. 127 (13) (2005) 4930-4934.

[9] O. M. Wilson, R. W. J. Scott, J. C. Garcia-Martinez, R. M. Crooks, Synthesis, characterization, and structure-selective extraction of 1-3-nm diameter AuAg dendrimer-encapsulated bimetallic nanoparticles, J. Am. Chem. Soc. 127 (2005) $1015-1024$.

[10] M. R. Knecht, M. G. Weir, A. I. Frenkel, R. M. Crooks, Structural rearrangement of bimetallic alloy pdau nanoparticles within dendrimer templates to yield core/shell configurations, Chem. Mater. 20 (3) (2008) 1019-1028.

[11] M. G. Weir, M. R. Knecht, A. I. Frenkel, R. M. Crooks, Structural analysis of pdau dendrimer-encapsulated bimetallic nanoparticles, Langmuir 26 (2) (2010) $1137-1146$.

[12] S. V. Myers, A. I. Frenkel, R. M. Crooks, X-ray absorption study of pdcu bimetallic alloy nanoparticles containing an average of 64 atoms, Chem. Mater. 21 (20) (2009) 4824-4829. 
[13] E. V. Carino, R. M. Crooks, Characterization of pt@cu core@ shell dendrimerencapsulated nanoparticles synthesized by cu underpotential deposition, Langmuir 27 (2011) 4227-4235.

[14] D. F. Yancey, E. V. Carino, R. M. Crooks, Electrochemical synthesis and electrocatalytic properties of au@pt dendrimer-encapsulated nanoparticles, J. Am. Chem. Soc. 132 (2010) 10988-10989.

[15] D. F. Yancey, L. Zhang, R. M. Crooks, G. Henkelman, Au@pt dendrimer encapsulated nanoparticles as model electrocatalysts for comparison of experiment and theory, Chem. Sci. 3 (2012) 1033-1040.

[16] R. M. Anderson, L. Zhang, J. A. Loussaert, A. I. Frenkel, G. Henkelman, R. M. Crooks, An experimental and theoretical investigation of the inversion of pd@pt core@shell dendrimer-encapsulated nanoparticles, ACS Nano 7 (10) (2013) 9345-9353.

[17] L. Zhang, R. Iyyamperumal, D. F. Yancey, R. M. Crooks, G. Henkelman, Design of pt-shell nanoparticles with alloy cores for the oxygen reduction reaction, ACS Nano 7 (10) (2013) 9168-9172.

[18] J. Zhang, Y. Mo, M. B. Vukmirovic, R. Klie, K. Sasaki, R. R. Adzic, Platinum monolayer electrocatalysts for $\mathrm{O}_{2}$ reduction: Pt monolayer on $\mathrm{Pd}(111)$ and on carbon-supported Pd nanoparticles, J. Phys. Chem. B 108 (2004) 10955-10964.

[19] W. Tang, G. Henkelman, Charge redistribution in core-shell nanoparticles to promote oxygen reduction, J. Chem. Phys. 130 (2009) 194504.

[20] J. K. Nørskov, J. Rossmeisl, A. Logadottir, L. Lindqvist, J. R. Kitchin, T. Bligaard, H. Jónsson, Origin of the Overpotential for Oxygen Reduction at a FuelCell Cathode, J. Phys. Chem. B 108 (2004) 17886-17892.

[21] T. Bligaard, J. Nørskov, S. Dahl, J. Matthiesen, C. Christensen, J. Sehested, The brønsted-evans-polanyi relation and the volcano curve in heterogeneous catalysis, J. Catal. 224 (2004) 206-217.

[22] J. L. Fernández, D. A. Walsh, A. J. Bard, Thermodynamic Guidelines for the Design of Bimetallic Catalysts for Oxygen Electroreduction and Rapid Screening by Scanning Electrochemical Microscopy, J. Am. Chem. Soc. 127 (2005) 357365.

[23] V. R. Stamenkovic, B. Fowler, B. S. Mun, G. Wang, P. N. Ross, C. A. Lucas, N. M. Marković, Improved oxygen reduction activity on $\mathrm{Pt}_{3} \mathrm{ni}(111)$ via increased surface site availability, Science 315 (2007) 493-497.

[24] S. Koh, P. Strasser, Electrocatalysis on bimetallic surfaces: Modifying catalytic reactivity for oxygen reduction by voltammetric surface dealloying, J. Am. Chem. Soc. 129 (2007) 12624-12625. 
[25] O. Savadogo, K. Lee, K. Oishi, S. Mitsushima, N. Kamiya, K.-I. Ota, New palladium alloys catalyst for the oxygen reduction reaction in an acid medium, Electrochem. Comm. 6 (2004) 105-109.

[26] C.-Y. Lu, G. Henkelman, Role of geometric relaxation in oxygen binding to metal nanoparticles, J. Phys. Chem. Lett. 2 (11) (2011) 1237-1240.

[27] W. Tang, L. Zhang, G. Henkelman, Catalytic activity of pd/cu random alloy nanoparticles for oxygen reduction, J. Phys. Chem. Lett. 2 (2011) 1328-1331.

[28] F. Fouda-Onana, S. Bah, O. Savadogo, Palladium-copper alloys as catalysts for the oxygen reduction reaction in an acidic media i: Correlation between the orr kinetic parameters and intrinsic physical properties of the alloys, J. Electroanal. Chem. 636 (2009) 1-9.

[29] X. Wang, N. Kariuki, J. T. Vaughey, J. Goodpaster, R. Kumar, D. J. Myers, Bimetallic Pd-Cu oxygen reduction electrocatalysts, J. Electrochem. Soc 155 (2008) B602-B609.

[30] B. Hammer, J. K. Nørskov, Why gold is the noblest of all the metals, Nature 376 (1995) 238-240.

[31] N. S. Froemming, G. Henkelman, Optimizing core-shell nanoparticle catalysts with a genetic algorithm, J. Chem. Phys. 131 (23) (2009)-.

[32] J. X. Wang, H. Inada, L. Wu, Y. Zhu, Y. Choi, P. Liu, W.-P. Zhou, R. R. Adzic, Oxygen reduction on well-defined coreshell nanocatalysts: Particle size, facet, and pt shell thickness effects, J. Am. Chem. Soc. 131 (47) (2009) 17298-17302.

[33] K. Gong, D. Su, R. R. Adzic, Platinum-monolayer shell on auni0.5fe nanoparticle core electrocatalyst with high activity and stability for the oxygen reduction reaction, J. Am. Chem. Soc. 132 (41) (2010) 14364-14366.

[34] S. Pande, S. K. Ghosh, S. Praharaj, S. Panigrahi, S. Basu, S. Jana, A. Pal, T. Tsukuda, T. Pal, Synthesis of normal and inverted goldsilver coreshell architectures in -cyclodextrin and their applications in sers, J. Phys. Chem. C 111 (29) (2007) 10806-10813.

[35] P.-P. Fang, S. Duan, X.-D. Lin, J. R. Anema, J.-F. Li, O. Buriez, Y. Ding, F.-R. Fan, D.-Y. Wu, B. Ren, Z. L. Wang, C. Amatore, Z.-Q. Tian, Tailoring au-core pd-shell pt-cluster nanoparticles for enhanced electrocatalytic activity, Chem. Sci. 2 (2011) 531-539.

[36] A. U. Nilekar, Y. Xu, J. Zhang, M. Vukmirovic, K. Sasaki, R. Adzic, M. Mavrikakis, Bimetallic and ternary alloys for improved oxygen reduction catalysis, Top. Catal. 46 (3-4) (2007) 276-284.

[37] F.-J. Lai, H.-L. Chou, L. S. Sarma, D.-Y. Wang, Y.-C. Lin, J.-F. Lee, B.-J. Hwang, C.-C. Chen, Tunable properties of ptxfe1-x electrocatalysts and their catalytic activity towards the oxygen reduction reaction, Nanoscale 2 (2010) 573-581. 
[38] G. Barcaro, A. Fortunelli, M. Polak, L. Rubinovich, Patchy multishell segregation in pdpt alloy nanoparticles, Nano Lett. 11 (4) (2011) 1766-1769.

[39] J. Hernández, J. Solla-Gullón, E. Herrero, A. Aldaz, J. M. Feliu, Characterization of the surface structure of gold nanoparticles and nanorods using structure sensitive reactions, J. Phys. Chem. B 109 (26) (2005) 12651-12654.

[40] J. Hernández, J. Solla-Gullón, E. Herrero, A. Aldaz, J. M. Feliu, Electrochemistry of shape-controlled catalysts: oxygen reduction reaction on cubic gold nanoparticles, J. Phys. Chem. C 111 (38) (2007) 14078-14083. arXiv:http://dx.doi.org/10.1021/jp0749726, doi:10.1021/jp0749726.

URL http://dx.doi.org/10.1021/jp0749726

[41] J. Hernández, J. Solla-Gullón, E. Herrero, J. M. Feliu, A. Aldaz, In Situ surface characterization and oxygen reduction reaction on shape-controlled gold nanoparticles, J. Nanosci. Nanotechnol. 9 (4) (2009) 2256-2273.

[42] E. V. Carino, H. Y. Kim, G. Henkelman, R. M. Crooks, Site-selective cu deposition on pt dendrimer-encapsulated nanoparticles: Correlation of theory and experiment, J. Am. Chem. Soc. 134 (9) (2012) 4153-4162.

[43] R. Iyyamperumal, L. Zhang, G. Henkelman, R. M. Crooks, Efficient electrocatalytic oxidation of formic acid using au@pt dendrimer-encapsulated nanoparticles, J. Am. Chem. Soc. 135 (15) (2013) 5521-5524.

[44] M. H. Shao, K. Sasaki, R. Adzic, Pd-Fe nanoparticles as electrocatalysts for oxygen reduction, J. Am. Chem. Soc. 128 (2006) 3526-3527.

[45] K. Sasaki, H. Naohara, Y. Choi, Y. Cai, W.-F. Chen, P. Liu, R. R. Adzic, Highly stable pt monolayer on pdau nanoparticle electrocatalysts for the oxygen reduction reaction, Nat. Commun. 3 (2012) 1115.

[46] L. Zhang, G. Henkelman, Tuning the oxygen reduction activity of pd shell nanoparticles with random alloy cores, J. Phys. Chem. C 116 (2012) 2086020865 .

[47] L. Zhang, G. Henkelman, Computational design of alloy-core@ shell metal nanoparticle catalysts, ACS Catal. 5 (2014) 655-660.

[48] L. Zhang, H. Y. Kim, G. Henkelman, Co oxidation at the au-cu interface of bimetallic nanoclusters supported on ceo2(111), J. Phys. Chem. Lett. 4 (2013) 2943-2947. 